\section{Psicanálise e pesquisa}

\section{Psychoanalysis and research}

Desde seus anos iniciais, a psicanálise inclui a pesquisa em sua própria definição, pois com tal nome Freud propunha designar "1) um procedimento para a investigação de processos mentais que são quase inacessíveis por qualquer outro método; 2) um método (baseado nessa investigação) para o tratamento de distúrbios neuróticos; e 3) uma coleção de informações psicológicas obtidas ao longo dessas linhas e que, gradualmente, se acumulam numa nova disciplina científica“. ${ }^{1}$

Na essência mesma do método psicanalítico está a noção de que tratamento e investigação são concomitantes, pois o curso de um processo analítico tem como parte central a idéia de que se trata de um procedimento em que analista e paciente estudam, de forma compartilhada, as expressões, os significados e as rotas históricas que produzem o sofrimento psíquico atual deste. Nas últimas décadas, com o crescente refinamento do método analítico, cada vez mais se incluem a mente do analista e o campo bipessoal que este constitui com o paciente como elementos centrais da investigação.

Como ocorre com as demais disciplinas científicas, a psicanálise necessita da pesquisa para continuar produzindo conhecimento, não se estagnar em fórmulas repetitivas e encontrar sempre novas formas de diálogo com outros saberes.

Quais são os desafios contemporâneos que tal relação nos propõe?

Penso que tais desafios têm a ver com a definição do termo pesquisa, com os métodos a serem empregados na pesquisa e com a maior ou menor disponibilidade de psicanalistas e pesquisadores em buscar maneiras de compatibilizar a especificidade da psicanálise com as exigências da pesquisa.

Assim sendo, se considerarmos um conceito amplo de pesquisa e se admitirmos que pelo menos três abordagens de investigação podem ser adotadas - a saber: a pesquisa empírica, a conceitual e a clínica-, teremos a possibilidade de distinguir diferentes cenários em que pesquisa e psicanálise podem ter encontros frutíferos.

Podemos ainda diferenciar a pesquisa psicanalítica propriamente dita, ou seja, aquela que é efetuada com o método psicanalítico em si, dentro da sessão ou do processo analítico, e a pesquisa em psicanálise, ou seja, aquela que usa conceitos psicanalíticos e os diferentes métodos de investigação para testá-los ou aplicá-los em outros cenários clínicos ou teóricos. O trabalho de Blaya et al. sobre mecanismos de defesa nos diferentes quadros psiquiátricos é um eloqüente exemplo desta segunda acepção. ${ }^{2}$ Exemplos similares incluem estudos sobre processo e resultados das psicoterapias psicanalíticas, relações entre trauma infantil e doença mental na vida adulta, contratransferência e sua relevância para a prática psicoterápica e sua supervisão para citar apenas alguns.

A pesquisa empírica em psicanálise tem apresentado crescentes estudos e uma das áreas mais amplamente contempladas tem sido a dos estudos de efetividade, que revelam evidências consistentes acerca da relevância do método psicanalítico, lançando mão tanto de estudos quantitativos como qualitativos..$^{3-4}$ Embora a experiência clínica acumulada em mais de 100 anos de efetivo trabalho não dê lugar a quaisquer dúvidas na mente dos analistas experientes e dos pacientes e suas famílias, tais 
estudos nos permitem um diálogo mais amplo com a psiquiatria baseada em evidências.

Assim, a pesquisa clínica é a matéria prima por excelência da psicanálise, tanto através dos estudos de caso único como de seqüências de casos - talvez o método de pesquisa mais adequado ao objeto de investigação - e é dela que provém a maioria dos insights obtidos até o momento.

Por sua vez, a pesquisa conceitual, que tem recebido atenção crescente, permite refinar, precisar e examinar com minúcia o desenvolvimento e as transformações de conceitos e suas complexas interações com os sistemas teóricos que habitam ou co-habitam. ${ }^{5}$

Dentre as controvérsias atuais na comunidade psicanalítica, uma das mais candentes confronta os que defendem que a interlocução específica da psicanálise é com as ciências humanas e os que propõem que deva continuar buscando o diálogo com as ciências naturais. Penso que ambas as formas de comunicação são imprescindíveis e que avanços consideráveis têm sido obtidos tanto no estabelecimento da neuropsicanálise quanto no diálogo com a filosofia, a crítica literária, a história e a antropologia. ${ }^{6}$

No que se refere à relação entre a psicanálise e a psiquiatria, da mesma forma que o papel da pesquisa nesta complexa relação, temos um importante desafio a enfrentar, que demanda uma capacidade de escuta e de interlocução consideráveis.

Concretamente, penso que os programas de pós-graduação em psiquiatria necessitam preservar e desenvolver a área de pesquisa em psicanálise, incluindo e reconhecendo a inestimável contribuição das pesquisas qualitativas, possivelmente as mais específicas para estes estudos. Além disto, as publicações psiquiátricas necessitam manter ou ampliar espaços para pesquisas psicanalíticas, e os sistemas de avaliação de produção científica, como a CAPES (Coordenação de Aperfeiçoamento de Pessoal de Nível Superior), necessitam revisar alguns critérios que excluem boas publicações psicanalíticas ou psicoterápicas do rol dos periódicos mais valorizados.

De sua parte, os pesquisadores em psicanálise necessitam desenvolver maior sofisticação nos diferentes métodos de pesquisa.

Tais medidas se impõem pela simples razão de que nossa disciplina necessita preservar e desenvolver suas ciências básicas uma das quais é a psicanálise -, a partir das quais se originam os principais métodos terapêuticos e cujo conjunto nos torna mais capazes de exercer a verdadeira razão de nossa existência, ou nossa relevância como empreendimento humano.

Por mais dificuldades que existam neste convívio, psiquiatria e psicanálise necessitam-se mutuamente; ignorar tal fato não é apenas um estreito reducionismo, senão uma lamentável negligência médica.

Cláudio Laks Eizirik Departamento de Psiquiatria e Medicina Legal, Faculdade de Medicina, Universidade Federal do Rio Grande do Sul (UFRGS), Porto Alegre (RS), Brasil

\section{Referências}

1. Freud S. Dois Verbetes de Enciclopédia. In: Edição Standard Brasileira das Obras Psicológicas Completas. Rio de Janeiro: Imago; 1976

2. Blaya C, Dornelles M, Blaya R, Kipper L, Heldt E, Isolan L, Bond M, Manfro GG. Do defense mechanisms vary according to psychiatric disorder? Rev Bras Psiquiatr. 2006;28(3):179-84.

3. Fonagy P. An open door review of outcome studies in psychoanalysis. 2nd ed. London: International Psychoanalytical Association; 2002. 330 p.

4. Leuzinger-Bohleber M, Stuhr U, Ruger B, Beutel M. How to study the 'quality of psychoanalytic treatments' and their long-term effects on patients' well-being: a representative, multi-perspective follow up study. Int J Pychoanal. 2003;84(Pt 2):263-90.

5. Dreher AU. What does conceptual research have to offer? In: Leuzinger-Bohleber M, Dreher V, Canestri J, eds. Pluralism and Unity? Methods of Research in Psychoanalysis. London: International Psychoanalytical Association; 2003. 274p.

6. Eizirik CL. Psychoanalysis as a work in progress. Int J Psychoanal. 2006;87:645-50. 